\title{
La conducta implícita en la relación bipersonal
}

Fernando Lolas Stepke

Universidad de Chile

Recibido: 12 de enero del 2012 / Aprobado: 21 de febrero del 2012

Este artículo destaca el valor heurístico de la dimensión implícito-explícito en el estudio de la conducta manifiesta y elabora algunos aspectos de su relevancia en la investigación psicoterapéutica. Por conducta implícita se entiende aquel comportamiento manifiesto, tanto informativo como comunicativo, que no se entiende mediante las pautas y normas de lo lingüisticamente organizado y posee una semántica y una pragmática que apelan a la experiencia intuitiva. Dentro de la categoría de lo implícito se consideran conductas motoras, mensajes emanados de la gestualidad y elementos del habla que no se reducen al contenido verbal.

conducta implícita / psicoterapia / comunicación no verbal

\section{Implicit behavior on bipersonal relationship}

This paper emphasizes the heuristic value of the implicit-explicit dimension in the study of overt behavior and develops some aspects of its relevance in psychotherapy research. The notion of implicit behavior includes overt behavior, informative and communicative, not understood using the rules of linguistically organized behavior and possessing a semantics and a pragmatics that demand an intuitive experience. Within the category of implicit are considered motor behaviors, messages emanating from gestural activities and speech elements not reducible to verbal contents.

implicit behavior / psychotherapy / non verbal communication

Correo electrónico: flolas@u.chile.cl 


\section{EL CONCEPTO DE CONDUCTA IMPLÍCITA}

En un artículo publicado anteriormente (Lolas \& Ferner, 1978) dimos la denominación de conducta implícita al comportamiento manifiesto (esto es, visible, mediado tanto por el sistema autónomo como cerebroespinal) que informa o comunica sobre las características del individuo que lo manifiesta. La expresión implícito indica que no se trata de una semántica lingüísticamente organizada (aunque para hacer comprensible este comportamiento deba a veces recurrirse al lenguaje, lo que ya supone una "traducción"). De sus dos formas, la que llamamos comunicativa tiene intención de "expresar" algo (por ejemplo, los ademanes que acompañan a la expresión verbal para darle énfasis, negarla o subrayarla). A su vez, la conducta informativa manifiesta estados o rasgos sin la intención expresa de parte del emisor (por ejemplo, enrojecer de vergüenza en una situación social). Lo central del continuo implícito-explícito que se proponía en ese texto es la importancia relativa de claras reglas de codificación y decodificación, de naturaleza biológica o social. Afirmábamos que pueden existir comportamientos parcialmente implícitos, o con componentes implícitos, en un flujo informativo-comunicacional entre dos o más individuos.

La obra pionera de Darwin sobre la expresión de las emociones ha sido la inspiración de generaciones de etólogos y estudiosos de lo que suele llamarse el comportamiento no verbal de la especie humana. En ese trabajo pionero, Darwin distinguió entre los hábitos asociados útiles y los simples concomitantes fisiológicos de los estados emocionales (Lolas, 1979, 1981, 1982, 1985, 1994).

Si bien las emociones son importantes en la interacción bipersonal, no son lo único que se manifiesta o intercambia. Hay gestos codificados por la cultura o la costumbre, a veces idiosincrásicos de grupos o individuos, que informan o comunican manteniendo neutralidad emocional. En ese caso, predomina el contenido no emotivo; por ejemplo, la señal con que un policía me prohíbe cruzar la calle (ejemplo orteguiano) aunque puede generar en mí una respuesta emocional no manifiesta necesariamente emociones del emisor. De hecho, Ortega usa el ejemplo para señalar una conducta social "in humana" porque es la ley, y no la persona, la que manifiesta esa prohibición. Esto es, cuando el policía hace un ademán prohibiendo, no es él como persona quien "habla" sino la sociedad y la ley que se expresan "a través" suyo. Este expresarse a través del cuerpo rige los rituales sociales y religiosos mediante códigos a veces imperceptibles o válidos dentro de una comunidad determinada e incluye acciones diferidas o cristalizadas en atuendos, vestimentas, formas de acomodar el cabello o pilosidades intencionales (como en algunas religiones que prescriben barba a sus adeptos). 
La semantización del comportamiento (o conversión a significaciones) exige conocimiento de los códigos si se desea hacer inferencias pragmáticas. Una inferencia pragmática informa sobre la relación entre el emisor del mensaje y los signos y símbolos que emite. Esta inferencia puede apuntar a reconstruir "estados interiores" (entre otros, las emociones) o a anticipar determinados comportamientos (conductas amenazantes pueden predecir ataque). Si este conocimiento se emplea con fines diagnósticos, pronósticos o terapéuticos es necesario contar con un sistema de desciframiento que indique la validez de la inferencia y la confiabilidad del proceso de observación. Obviamente, también hay un reconocimiento implícito, pues los observadores no reciben un mensaje si no tienen recursos conceptuales o icónicos para decodificar. Es posible imaginar situaciones en las cuales todo un ritual social observado por alguien de una cultura ajena a aquella en que se realiza sea por completo ininteligible, como de hecho ocurre en situaciones cotidianas cuando se visita un país extraño. La interpretación del comportamiento, del vestido, de los gestos puede dar lugar a valoraciones positivas o negativas en el contexto de las prácticas sociales, y de hecho las origina frecuentemente.

La valoración se traduce en actitudes y respuestas, a veces no conscientes o formalizadas, lo cual permite distinguir en ese plano entre lo que es esperable y lo que es impensado. A menudo, las expectativas inconscientes determinan la forma en que se reciben y valoran los mensajes.

\section{CONDUCTA IMPLÍCITA E INVESTIGACIÓN PSICOTERAPÉUTICA}

En un proceso de interacción bipersonal sistemática, regida por una teoría aceptable del comportamiento humano, con finalidades diagnósticas y terapéuticas, el trato (Umgang) y el encuentro (Begegnung) adquieren características especiales. Son susceptibles de exploración con base en hipótesis que puedan apoyarse en informaciones empíricas relativas a los participantes del encuentro, la situación en que este se realiza, la teoría que subyace o las consecuencias esperadas o inesperadas de la interacción. Todo ello puede verificarse desde el "exterior" de la situación, o -lo que es más complejo- desde "dentro" de ella.

En la investigación "desde dentro" en psicoterapia solamente es posible de aceptarse como válidos los datos que arroja la observación reglada de procesos que involucran al observador como participante. Las exigencias pasan por depurar la capacidad de este para separar los datos de la reacción que ellos generan en el investigador. Otras metodologías involucran el análisis de las formas de emisión del lenguaje, las gestualidades y las reacciones de los participantes a estímulos controlados. 
Tradicionalmente, el campo suele dividirse en estudios que abordan el proceso y aquellos que se centran en los resultados. Las variables independientes pueden referirse al paciente (o cliente), al terapeuta, a la situación y a condicionantes propios de la técnica empleada. La principal dificultad estriba en el carácter y solidez de las inferencias causales relativas a la importancia de algunos factores que se consideran relevantes.

Como en otros tipos de investigación empírica, la finalidad es lograr certidumbres basadas en procesos públicos y replicables, con un apropiado grado de "generalizabilidad".

En estudios clásicos de la literatura psicoanalítica, el material de observación y la fuente de datos para inferencias proceden de lo que proporciona un solo sujeto, observado longitudinalmente por períodos prolongados. La generalización heurística, o interpretativa, apunta a iluminar la comprensión que un lector con semejante formación $\mathrm{y}$ experiencia pueda tener de casos semejantes. También contribuye de manera importante a la propia autocomprensión del investigador-terapeuta, quien refina su capacidad de observación y análisis. En este tipo de estudios puede afirmarse que el órgano de la comprensión es un inconsciente entrenado. El "caso clínico" es una herramienta que identifica un tipo de cognición particular y apunta a una audiencia preparada para aprovechar su contenido informativo.
Conocida es la afirmación de Freud de que en la terapia analítica lo que ocurre es un intercambio de palabras, haciendo del lenguaje el medio privilegiado del cambio terapéutico y del oído el órgano por excelencia para la recolección de informaciones. La "talking cure", como la denominó la paciente Anna $\mathrm{O}$, se perfeccionó con procedimientos que parecían excluir, por no fundamentales, los datos proporcionados por la vista o el tacto. No es de extrañar que a lo largo de la historia de las psicoterapias, aun de las inspiradas psicodinámicamente, haya habido propuestas de incorporar otros canales sensoriales a la experiencia bipersonal o grupal (Senf \& Broda, 2012).

La pregunta central que debe responderse concierne a la relevancia de las informaciones. Si solamente importan los afectos expresados en el habla tanto para inducir cambios biográficos como para evaluarlos en su valencia terapéutica, entonces es el habla la que interesa. Durante muchos años trabajamos con técnicas de análisis del contenido verbal para cuantificar afectos expresados en el lenguaje hablado. Pudimos describir estilos de interacción terapeuta-cliente con relevancia nosográfica, como la presencia de alexitimia en algunos grupos de individuos. Seguimos la evolución de la expresión afectiva intrasesión y entre sesiones. En relación con el resultado de la experiencia psicoterapéutica, el método de Gottschalk y Gleser, modificado por 
nosotros, sirvió para comprobar cambios en variables relevantes, como las expresiones de ansiedad, hostilidad o esperanza (Gottschalk et al., 1986; Lolas, 1990).

Mirados retrospectivamente, muchos de estos estudios no evitan la circularidad de medir aquello que se puede medir y declararlo importante solo porque es medible. El impacto del cambio terapéutico es significativo en realidad cuando se manifiesta fuera del contexto de la terapia, en la vida corriente. De hecho, la cura psicoanalítica es interminable y de verdad termina cuando se acepta que es interminable. Los comportamientos manifiestos no siempre traducen a cabalidad los cambios intrapsíquicos.

Dentro de los estudios de conducta implícita del proceso psicoterapéutico, es de singular relevancia el estudio publicado por Christian-Widmaier en 2008. Es un libro que parte de dos fundamentos metódicos, la observación participante y el análisis cualitativo de cuatro comportamientos: el diálogo de las miradas, el diálogo de las manos, la salida al inodoro y el manejo de las puertas. Se trata de comportamientos que ocurren en las interacciones cotidianas entre personas pero que, en el caso de la terapia, son parte de situaciones limítrofes entre lo propiamente terapéutico y lo simplemente social. El cliente saluda y se despide de su terapeuta, interactúa con él/ella durante la sesión más allá, o fuera de, lo esperable en esa situación y de ese modo, para el observador entrenado, provee informaciones que a veces son importantes para conducir o reconducir el proceso. También es posible, según los códigos aceptados, que los gestos, las miradas y los comportamientos sean utilizados deliberadamente para comunicar en paralelo con, o incluso en oposición a, lo comunicado verbalmente.

En los próximos acápites, tomando como fundamento el estudio sociológico-psicoanalítico de esta autora, contra el trasfondo de nuestros estudios previos, analizaremos algunas dimensiones del acto como fuente de informaciones y como elemento para evaluar personas y situaciones en una forma sincrónica y diacrónica.

\section{CONDUCTA Y PRAXIS. EL VALOR DE LA} DIMENSIÓN IMPLÍCITO-EXPLÍCITO

Hay que restablecer una distinción fundamental. El acto humano puede ser categorizado desde dos puntos de vista distintos y complementarios. Cuando Watson proponía la noción de conducta como núcleo de la naciente ciencia psicológica se basaba en que se trata de un observable que puede permitir cierto grado de objetividad. El conductismo metafísico no logró desechar por completo la idea de estados interiores, pero redujo el problema a saber qué determinaciones se precisan para algunos comportamientos y qué consecuencias tienen estos para el desarrollo de patrones de comportamiento. Las ideas de 
refuerzo y sus patrones y la moldeabilidad del comportamiento fueron aportaciones significativas.

Con la noción de Handlung daba la sociología weberiana una dimensión diferente del acto humano. La praxis, traducción que preferimos a la de acción, es un movimiento con sentido, que inicia algo así como una narración cuyo final es un significado social. Cuando alguien se pinta la cara, por ejemplo, el sentido es ese, pintarse la cara, pero la significación puede darse en un plano muy amplio de narraciones: puede ser para llamar la atención de alguien, puede tener por finalidad impresionar o puede ser parte de una preparación escénica. El sentido del acto se complementa así con un significado que dependerá del contexto interpretativo que se escoja, de la circunstancia y de la valencia biográfica (a menudo desconocida hasta para el propio actor). En el juego de la vida diaria se es actor y agente, pues se muestra y se opera.

Existe una estética del acto y también una ética del acto. El verdadero acto humano nunca es puro y simple movimiento sino manifestación de una intención que algo espera, a algo aspira y algo desea concretar. Es el comienzo de una historia, de una narración, cuya conclusión da lugar a un significado, según lo que hemos ilustrado antes. En su obra Vom Wertbewusstsein im Tun (1948) dio mi maestro Paul Christian algunas intuiciones de gran valor para enjuiciar lo apropiado o inapropiado del actuar humano, en el sentido de una praxis significativa. El "buen actuar" es un actuar que inspira un sentimiento de plenitud en el observador. Es lo "justo", lo "logrado", lo "apropiado". Un acto bien hecho, obsérvese bien, no es necesariamente un acto "bueno". Un asesinato puede ser bien hecho, pero no puede decirse que sea bueno, por más que Thomas De Quincey haya escrito que el asesinato puede estar dentro de las "bellas artes". Por lo tanto, la estética del acto no necesariamente es equiparable a la ética de su comisión. Es hasta posible que un buen acto, bello y justo, incluso con consecuencias positivas se troque, al paso del tiempo, en algo inadecuado o malo.

Hay por ende en el acto, en la praxis humana, un conjunto de valores. Estéticos algunos, morales otros. Para enjuiciar la moralidad ha de tenerse presente el contexto social y la valencia interpersonal, pues la moral es costumbre, ethos, en el seno de una sociedad humana, que enjuicia y valora no solamente los resultados sino también las intenciones. La conducta implícita, en los sentidos antes señalados, puede ser una fuente de intuiciones sobre intenciones y resultados, que de este modo se hacen susceptibles de análisis, sirven para predecir comportamientos y permiten emitir juicios sobre quienes manifiestan la conducta, sea esta comunicativa (esto es, intencional) o informativa (esto es, demostrativa). El 
principal obstáculo es, por cierto, la posibilidad de engaño. Una persona puede comportarse en una forma no acorde con sus disposiciones interiores. La veracidad, más que la verdad, es lo que importa en el enjuiciamiento ético, pues la praxis discursiva de la palabra, del gesto y de la mostración precisa siempre de interpretaciones (Giannini, 2011). La hermenéutica de la vida cotidiana, que se ejerce involuntariamente todo el tiempo, permite la "lectura" de lo visto y de lo oído con arreglo a los propios recursos expresivos. De hecho, no puede haber comprensión ni interpretación, ni tan siquiera comunicación, si el receptor no dispone en su propio repertorio de signos, símbolos o emblemas, de posibilidades de significación adecuadas. La veracidad es la adecuación del sentido al significado en el contexto de una interpretación interactiva en la que participan los otros, la sociedad y sus usos. Cuando se habla, por ejemplo, de lo que es justo se quiere indicar que se adecua tanto a las intenciones e intereses de un individuo como a la "salud" del conjunto humano. Es la intersección entre lo esperado y lo realizado lo que cualifica la acción justa y es el sentido de la idea de prudencia (phrónesis), que es virtud de adecuaciones y precisas satisfacciones de expectativas.

Como proceso de interacción cualificado técnicamente, tiene la psicoterapia un potencial inmenso para develar algunas invariantes de la moralidad de los actos, tanto de los actos de habla como de los actos de la praxis motriz. De allí la importancia de rescatar la dimensión implícito-explícito como instrumento heurístico para su análisis y para derivar de allí intuiciones susceptibles de aplicación en otros campos.

\section{Referencias}

Christian, P. (1948). Vom Wertbewusstsein im Tun. Ein Beitrag zur Psychophysik der Willkürbewegung. Stuttgart: Ferdinand Enke Verlag.

Christian-Widmaier, P. (2008). Nonverbale Dialoge in der psychoanalytischen Therapie. Eine qualitativ-empirische Studie. Giessen: Psychosozial-Verlag.

Giannini, H. (2011). Notas acerca de la moralidad de la acción. Revista de Filosofía (Santiago), 67, 167-182.

Gottschalk, L. A., Lolas, F., \& Viney, L. (Eds.) (1986). Content Analysis of Verbal Behavior. Significance in clinical medicine and psychiatry. Berlin-Heidelberg-Nueva York: Springer Verlag.

Lolas, F. \& Ferner, H. (1978). Zum Begriff des impliziten Verhaltens. Zeitschrift für klinische Psychologie und Psychotherapie (Freiburg) 26, 223-233.

Lolas, F. (1979). Perspectivas psiquiátricas de la antropología etológica. Acta Psiquiátrica y Psicológica de 
América Latina (Buenos Aires), 25, 127-134.

Lolas, F. (1981). Etología y psiquiatría. Acta Psiquiátrica y Psicológica de América Latina, 27, 252-253.

Lolas, F. (1982). Sobre proxémica y espacio personal. Revista Chilena de Psicología, 5, 87-92.

Lolas, F. (1985). Sobre categorías de la conducta: Bases del estudio fisiológico. Neurobiología, 48, 119-132.

Lolas, F., \& Mayer, H. (Eds.) (1987). Perspectives on stress and stress- related topics. Berlin-HeidelbergNueva York: Springer Verlag.

Lolas, F. (1990). Del análisis de contenido al análisis de significado. Anales de Psiquiatría (Madrid) 6, 269-274.

Lolas, F. (1994). Darwin y el estudio científico del comportamiento. Folia Humanistica (Barcelona) 32, 313-320.

Senf, W., \& Broda, M. (Eds.). (2012). Praxis der Psychotherapie. Ein integratives Lehrbuch. Stuttgart: Thieme. 